consists of a powerful source of microwaves, which either makes the bird collapse insensible, or encourages it to fly rapidly away. In either case the effect soon wears off. But so far, no really effective method has been found to deal with the problem.

\section{SPACE}

\section{ELDO's Future Programme}

DESPITE the recent move by the four hard core launcher countries of ELDO to continue the development of the Europa rocket on a small club basis (Nature, 221, 790; 1969), it is still considered essential that a full ELDO ministerial meeting should take place soon. This would be to settle the financing of this year's programme (already effectively committed) in the face of a failure by the ELDO council to agree the 1969 budget at Christmas. The other problem that faces the organization is the status of the future programme (which must be started without delay) and of the operational uses of the completed rocket. This is where the proposed club of the Four comes in. At the Christmas council meeting both Britain and Italy said they were not interested in the future programme, which includes a sizable slice of the "present" Europa 1 project. Their argument was that the revisions to the 1966 plan are so substantial as to amount to a new programme not authorized by the 1966 agreement-thereby freeing Britain and Italy from their commitments.

The big practical problem is to guarantee the supply of Blue Streak boosters without definite orders from either ELDO or its rump. It is quite unreal to maintain. a production line and keep together the skilled teams on which this depends under such conditions. "What we need and have increasingly stressed over the past year", a British Space Division official said this week, "is a clear undertaking that ELDO or this sub-group wants delivery of this vehicle at a rate of not less than two a year for $\mathrm{X}$ years with such-and-such delivery, reliability, etc." Britain last year guaranteed supply of Blue Streaks "at cost" to ELDO if the other members wished to pursue the programme. It is not, apparently, under an obligation to provide Blue Streaks to a sub-group (such as the club of Four) "but we would wish to do so". Some hope of reaching a definite agreement on the supply of Blue Streaks is seen in a visit now fixed for next week of a group of eight experts from the club to the Blue Streak firms, Hawker Siddeley Dynamics and Rolls-Royce. They will be led by Mr J. Causse, head of France's CNES, who gave his name to the Causse report. The fact finding tour is expected to last 2 to 3 days and to include the rocket test facility at Spadeadam, Cumberland, where team integrity is a particularly crucial problem.

\section{SPACE \\ Afier Apollo 9}

THe Apollo 9 astronauts seemed, just before returning to the Earth, to have had a successful journey. Now the chances are high that NASA will be pressed to go for a Moon landing in May instead of the test of the lunar module in lunar orbit which is planned for Apollo 10. There are a number of reasons why NASA should resist. For one thing, the lunar module is still untried, and its designers must be worried about December's

\title{
Mathematicians' Reireat
}

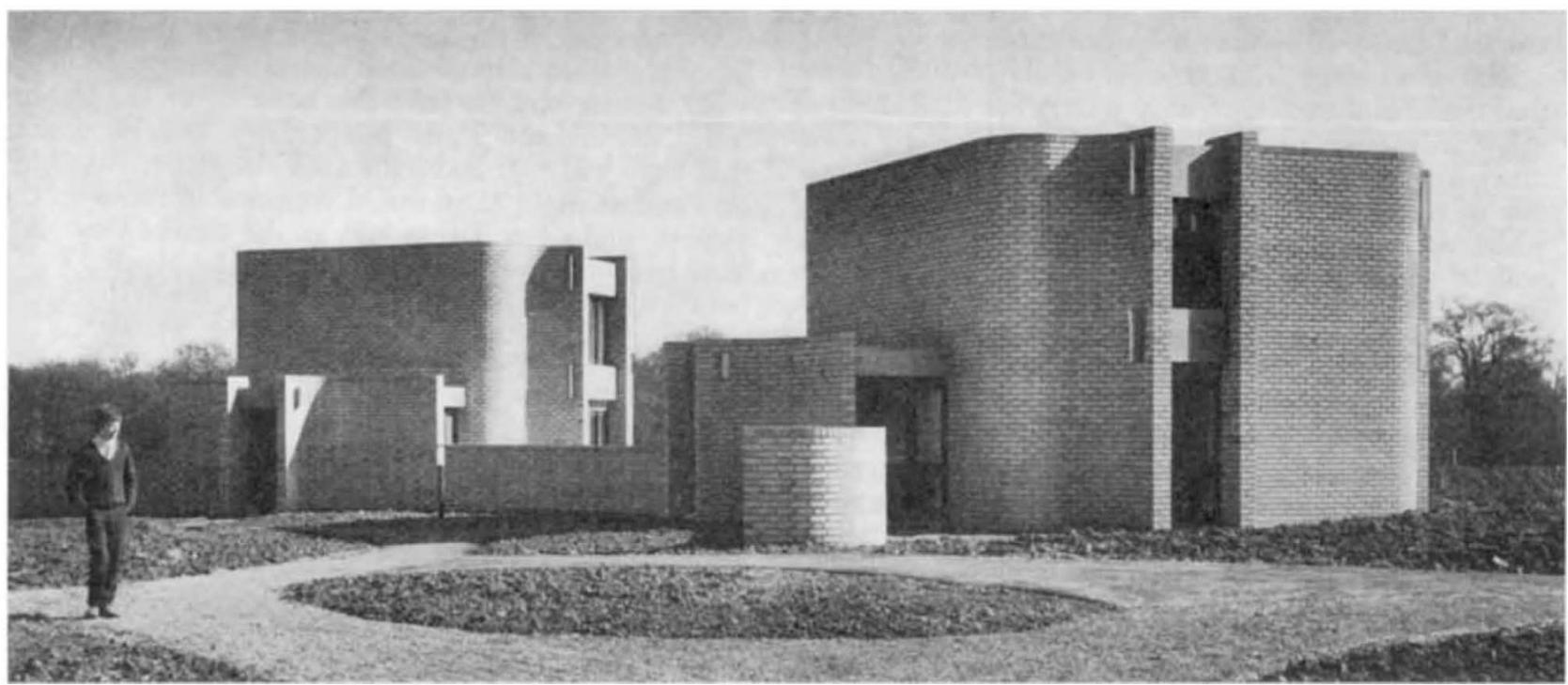

Two of the five houses which have been built at the University of Warwick to provide accommodation for visiting mathematicians. The scheme consists of five two-bedroomed houses and two one-bedroomed flats, each equipped with a study. The shape of the houses, the architects (Howell, Killick, Partridge and Amis) say, "derives from the need of mathematicians to have vast areas of blackboard, both as a work medium and a medium of communication". The walls of the studies consist almost entirely of blackboard. By enabling mathematicians to bring their wives-and children-the University of Warwick hopes to encourage distinguished scholars from abroad to come to seminars. (Children playing in the central courtyard will not be a disturbance, because the architects have deliberately not provided windows on that side.) 